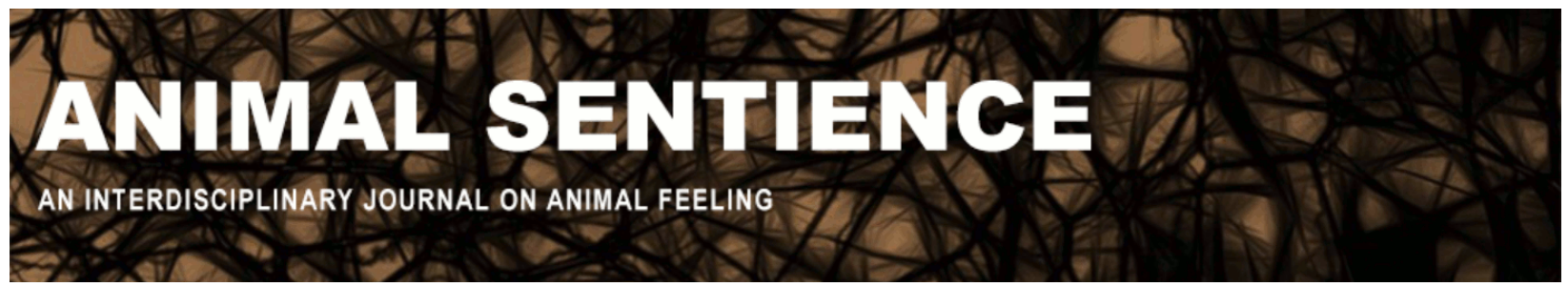

Gutfreund, Yoram (2017) Animal sentience? Neuroscience has no answers. Animal Sentience 13(4)

DOI: $10.51291 / 2377-7478.1231$

Date of submission: 2017-10-23

Date of acceptance: 2017-10-26

(c)

This article has appeared in the journal Animal

Sentience, a peer-reviewed journal on animal

cognition and feeling. It has been made open access,

free for all, by WellBeing International and deposited

in the WBI Studies Repository. For more information,

please contact

wbisr-info@wellbeingintl.org.

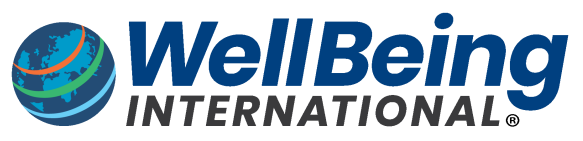

SOLUTIONS FOR PEOPLE, ANIMALS AND ENVIRONMENT 


\title{
Animal sentience? Neuroscience has no answers
}

Commentary on Woodruff on Fish Feel

\author{
Yoram Gutfreund \\ Department of Neurobiology \\ Technion
}

\begin{abstract}
Woodruff's target article provides a detailed review of comparative studies on brain and behavior in teleosts. However, the relevance of the scientific data to the question of consciousness rests solely on the validity of a small set of so-called "requirements for consciousness." I use the target article to demonstrate that the neuroscientific study of animal consciousness in general relies on external, highly questionable and unfalsifiable criteria, and therefore fails to resolve the question of which animal species are sentient. Fish behavior can be remarkably complex, but whether fish are conscious remains a matter of belief.
\end{abstract}

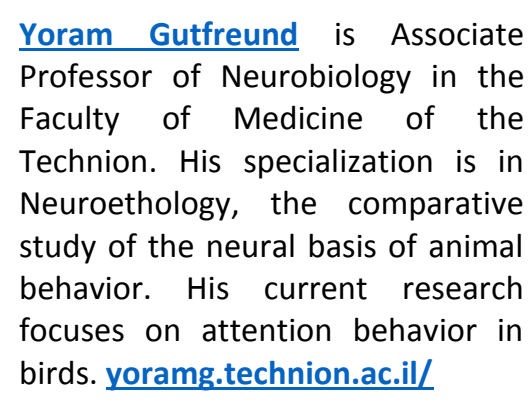

Yoram Gutfreund is Associate Professor of Neurobiology in the Medicine of the Technion. His specialization is in mparative behavior in birds. yoramg.technion.ac.il/

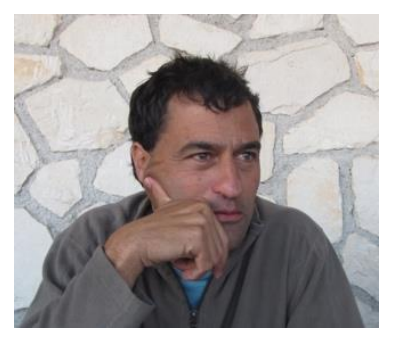

In a recent paper (Gutfreund 2017), I argued that scientific conclusions on consciousness in animals are mostly premature, and that given our current state of knowledge, neuroscientific data cannot help us resolve the question of animal consciousness, i.e., which animal species possess phenomenal consciousness or sentience. Woodruff's (2017) target article is a good example to illustrate this point.

The paper is divided into two parts: the first discusses the optic tectum, and the second the pallium. I will focus my comments on the first part. But the argument does not depend on a specific structure or behavior, and can therefore easily be generalized to the pallium as well as to publications about other species and brain structures.

Woodruff begins his discussion of the tectum with the following statement: "The neural representation of the world in the tectum is experienced subjectively as mental images." Here is how Woodruff justifies this: "But what evidence is there that the optic tectum is a crucial part of such a neural system? Others, in particular Feinberg and Mallatt $(2013,2016)$ and Merker (2007), have provided extensive reviews of this evidence. I will not replicate these reviews, but will provide a brief account of data indicating that the optic tectum, and its extrinsic and intrinsic connections, meet the requirements to be an anatomical substrate of sentience in fishes." [See also Mallatt \& Feinberg (2016) and Merker (2016) - ed.] 
Woodruff then explains what these requirements are: the first is that the visual world is represented accurately in the tectum and the second is the modulation of primary sensory pathways by intrinsic excitatory and inhibitory interneurons. This is followed by a review of the data supporting the above two "requirements" in fish. Therefore, the scientific data presented in the target article are not evidence for the main conclusion that there is something it feels like to be a fish but evidence for the "requirements," i.e., for sensory representations and neural modulation in the fish tectum. Woodruff's main conclusion rests on what seems to be axiomatic (and highly questionable) requirements. The question that is largely ignored in the paper is: what are the justifications for assuming that the requirements are indeed indicative of sentience in animals? I will now argue that the requirements are based on beliefs more than on scientific data, and since they are unfalsifiable, they fail to lead to progress.

Take the first requirement as an example: "isomorphic representation of sensory input and segregation of the sensory modalities." (On a side note, in my opinion the claim of isomorphic representation in the tectum is questionable in itself. There is compelling evidence, mostly from birds but also from fish, that the output layers of the tectum only represent the locations of relevant targets for behavior, rather than providing an accurate representation of what is out there [Mysore and Knudsen, 2011, Dutta and Gutfreund, 2014].) However, for the sake of argument, we can assume that the fish tectum represents the external environment in an isomorphic manner.

What reason is there to think that isomorphic representation is a criterion for sentience in fish? It is not in the biophysical properties of the neurons, it is not in the pathways from the sensory epithelium to the brain map, and it is not in the neural circuitry forming or modulating the representations. So what is left? The only reason to relate the mysterious property of consciousness to a sensory neural system representing the external environment is that we are aware of the world around us and therefore tend to relate consciousness to systems that represent the environment internally (metaphorically called mental images). I believe this same reason underlies all other suggested requirements for animal sentience: we are consciously aware of a unified coherent sensory space so we tend to relate consciousness to systems that integrate and bind sensory information. We are consciously aware of our declarative memories so we tend to relate consciousness to systems that demonstrate behavioral signatures of declarative memories, and so on. Consciousness in an animal is not inferred from what we know about its physics, chemistry or biology. At the moment, the only reason to justify inferring consciousness in an animal is that we are conscious. So the only way to resolve questions about consciousness in animals is by resolving our consciousness first. All the rest is anthropomorphism: if it behaves like me and has a brain with similarities to mine, it is likely to feel like me. This is an intuitive statement (and probably true) but it is not helpful because we are still faced with the unanswered question: how much like me does it need to be for it to be sentient? This is a different version of the original question of animal consciousness, taking us back to where we started. The lack of progress in resolving questions about consciousness in animals is the price to pay for ignoring the still existing explanatory gap between consciousness and behavior.

Closing remark. Woodruff concludes his paper with a surprising comment: "Fish sentience differs from human sentience, and what it feels like is as unknowable to us as what it feels like 
to be a bat." This comes as a surprise because much of the paper is an attempt to convince us that fish are sentient by showing how similar the organization of their brain and behavior is to those of mammals. The criteria for sentience are based on correlations to human sentience and so are the arguments in favor of the conclusions. So why is the final conclusion that fish sentience differs from that of humans? To me, this discrepancy is a sign that Woodruff admits somewhat the weaknesses of his evidence. The resemblance to humans is not the full story. There are also significant and meaningful anatomical, physiological and behavioral differences between conscious humans and fish. Since we do not know what the relationship between sentience and the brain or behavior is, it is equally possible that the differences dictate a sentience in fish that differs so much from that of humans that it cannot be called sentience anymore. The bottom line is that we do not know whether fish feel. The scientific evidence is good for those who already believe that they do.

\section{References}

Dutta, A. and Gutfreund, Y. (2014). Saliency mapping in the optic tectum and its relationship to habituation. Frontiers in Integrative Neuroscience, 8, 1.

Feinberg, T. E. and Mallatt, J. (2013). The evolutionary and genetic origins of consciousness in the Cambrian Period over 500 million years ago. Frontiers in Psychology, 4, 00667.

Feinberg, T. E. and Mallatt, J. M. (2016). The ancient origins of consciousness: how the brain created experience. Cambridge, MA: MIT Press.

Gutfreund, Y. (2017). The neuroethological paradox of animal consciousness. Trends in Neuroscience, 40, 196-199.

Mallatt, J. and Feinberg, T. E. (2016). Insect consciousness: Fine-tuning the hypothesis. Animal Sentience 9(10).

Merker, B. (2007). Consciousness without a cerebral cortex: a challenge for neuroscience and medicine. Behavioral and Brain Sciences, 30, 63-81.

Merker, B. (2016). Drawing the line on pain. Animal Sentience 3(23).

Mysore, S. P., and Knudsen, E. I. (2011). Flexible categorization of relative stimulus strength by the optic tectum. J of Neuroscience, 31, 7745-7752.

Woodruff, M. L. (2017). Consciousness in teleosts: There is something it feels like to be a fish. Animal Sentience 13(1). 


\section{ANIMAL CONSCIOUSNESS}

On November 17-18, 2017, the NYU Center for Mind, Brain and Consciousness, the NYU Center for Bioethics, and NYU Animal Studies will host a conference on Animal Consciousness.

This conference will bring together philosophers and scientists to discuss questions such as: Are invertebrates conscious? Do fish feel pain? Are nonhuman mammals self-conscious? How did consciousness evolve? How does research on animal consciousness affect the ethical treatment of animals? What is the impact of issues about animal consciousness on theories of consciousness and vice versa? What are the best methods for assessing consciousness in nonhuman animals?

\section{Speakers and panelists include:}

Colin Allen (University of Pittsburgh, Department of History \& Philosophy of Science), Andrew Barron (Macquarie, Cognitive Neuroethology), Victoria Braithwaite (Penn State, Biology), Peter Carruthers (Maryland, Philosophy), Marian Dawkins (Oxford, Zoology), Dan Dennett (Tufts, Philosophy), David Edelman (San Diego, Neuroscience),

Todd Feinberg (Mt. Sinai, Neurology), Peter Godfey-Smith (Sydney, Philosophy), Lori Gruen (Wesleyan, Philosophy), Brian Hare (Duke, Evolutionary Anthropology), Stevan Harnad (Montreal, Cognitive Science), Eva Jablonka (Tel Aviv, Cohn Institute), Björn Merker (Neuroscience), Diana Reiss (Hunter,

Psychology), Peter Singer (Princeton, Philosophy), Michael Tye (Texas, Philosophy)

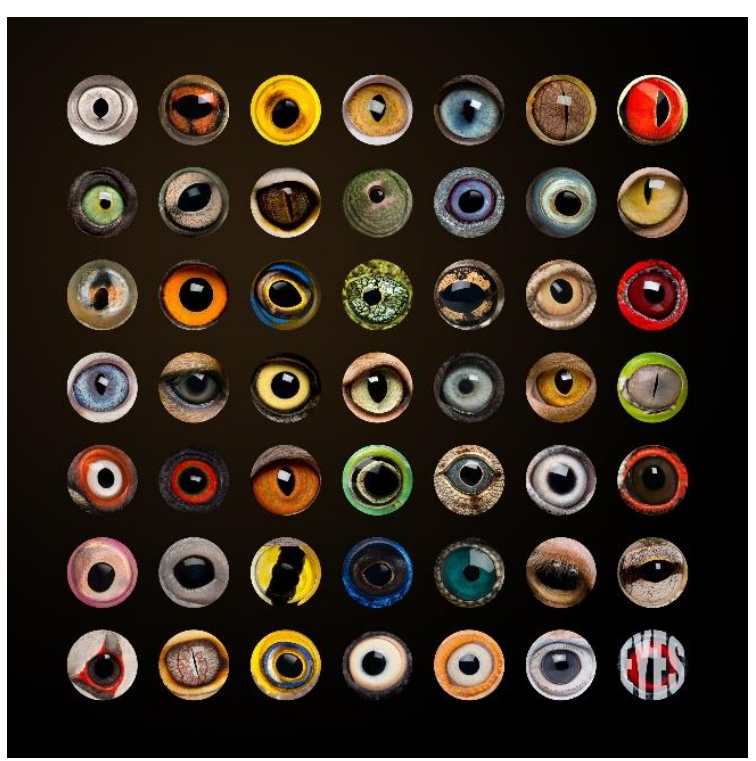

Organizers: Ned Block, David Chalmers, Dale Jamieson, S. Matthew Liao.

The conference will run from 9am on Friday November 17 to $6 \mathrm{pm}$ on Saturday November 18 at the NYU Cantor Film Center (36 E 8th St).

Friday sessions will include "Invertebrates and the evolution of consciousness", "Do fish feel pain?", and "Animal consciousness and ethics".

Saturday sessions will include "Animal self-consciousness", "Animal consciousness and theories of consciousness", and a panel discussion.

A detailed schedule will be circulated closer to the conference date.

Registration is free but required.

\section{Register here}

\section{See also the conference website}

